\title{
EFEITO DA SALINIZAÇÃO E DA ÉPOCA DE DISPERSÃO DAS SEMENTES NA EMERGÊNCIA DE PLÂNTULAS DE CANDEIA (Eremanthus erythropappus)
}

\author{
Flávia Freire de Siqueira, Tecnológa em Gestão Ambiental, flaviafreire lv@yahoo.com.br \\ Lilian Vilela Andrade Pinto, Instituto Federal de Educação, Ciência e Tecnologia do Sul de Minas Gerais - \\ Campus Inconfidentes, lilianvap@gmail.com. \\ Ademir José Pereira, Instituto Federal de Educação, Ciência e Tecnologia do Sul de Minas Gerais - \\ Campus Inconfidentes, mir@hardonline.com.br
}

\section{RESUMO}

Eremanthus erythropappus é uma espécie florestal nativa encontrada em grandes altitudes e contém pequenas exigências quanto ao clima, altidude, época de dispersão e exposição à salinização, para que ocorra a formação de um novo candeal. A espécie possui grande interesse econômico devido ao óleo (alfabisabolol) que é extraído de toda a planta. Os objetivos deste estudo foram: i) avaliar a influência do índice salino de diferentes adubos na emergência de plântulas de E. erythropappus; ii) indicar uma adubação para a semeadura direta desta espécie; iii) avaliar se a emergência de plântulas de candeia acompanham a sua época de dispersão. A semeadura realizada em viveiro ocorreu no inverno e na primavera em caixas de isopor de $15 \times 10 \mathrm{~cm}$ dispostas no delineamento inteiramente casualizado com 4 tratamentos (superfosfato simples, esterco bovino, formulado NPK 8-28-16 e testemunha) e 4 repetições com 100 sementes por caixa. A avaliação da emergência das plântulas foi diariamente durante 30 dias a partir da semeadura. Com os resultados obtidos podese concluir que a adubação com superfosfato simples, por apresentar baixo índice salino, é a mais eficiente para a semeadura direta em viveiro, podendo, portanto ser extrapolada para as condições de campo; e que a semeadura direta deve ocorrer na estação da primavera, período que corresponde a dispersão das sementes desta espécie.

Palavras-chave: Índice velocidade de emergência, época de semeadura, índice salino.

\section{INTRODUÇÃO}

A espécie Eremanthus erythropappus, conhecida como candeia, é encontrada em áreas montano-campestre desde o estado da Bahia até o Rio de Janeiro, em altitudes que variam de 1000 a 1700 m (NEMAF, 2003). Podem ocasionalmente aparecer em áreas de floresta mesófila, após perturbações levando a ocorrência de uma formação florestal chamada candeal (Tonetti et al., 2006). Quando isto acontece, o candeal aparece como uma formação pioneira, onde o número de indivíduos de E. erythropappus diminui gradativamente dando lugar a outras espécies, à medida que a floresta se torna mais estruturada (Pedralli, 1997).

Nos meses de agosto a setembro ocorre a floração das E. erythropappus, ocorrendo variações de lugar para lugar e de ano para ano, estes fatores estão diretamente relacionados com a umidade. As flores abrem de maio a agosto e o pico de floração é no mês de julho quando alguns indivíduos já começaram a frutificar, apresentando o pico entre os meses de setembro e outubro, quando se inicia a dispersão de sementes ou aquênios (Scolforo et al. 2005). A espécie apresenta porte arbóreo pequeno, podendo alcançar $10 \mathrm{~m}$ de altura e $30 \mathrm{~cm}$ de diâmetro na altura do peito, apresentando fuste irregular e curto e copa muito ampla (Rizzini, 1979).

A madeira desta espécie possui alta durabilidade, sendo muito requerida para a utilização como moirão esteios, lenha de ótima qualidade, caibros, carvão vegetal, postes, tacos, dormentes, vigas, etc (Chagas et al., 2007). 
Embora E. erythropappus produza moirões mais tarde do que o eucalipto, eles duram quatro a cinco vezes mais (Cândido, 1991). A lenha é de primeira, queimando mesmo verde e dando chama clara, porém a fumaça tem cheiro desagradável (Rizzini, 1979).

A espécie produz um óleo cujo principal componente é o alfabisabolol (Scolforo et al., 2005). As indústrias que produzem óleo de E. erythropappus pagam cerca de R $\$ 100,00$ pelo $\mathrm{m}^{3}$ de madeira colhida em florestas com planos de manejo aprovados pelos órgãos responsáveis. Por outro lado, quando a madeira é clandestina, ou seja, não tem origem comprovada, o preço do metro "estéreo" cai para R\$ 30,00 (Atina, 2009).

Coloniza facilmente solos pobres e sem préstimo agronômico, dando preferência aos arenosos (bem drenados) e não recusando os pedregosos (Rizzini, 1979 e Araújo, 1944). Isso, não quer dizer que ela não se adapte a terrenos melhores, pois, embora as plantas não morram quando plantadas em áreas amorradas, elas crescem lentamente (Cândido, 1991).

As necessidades de aumentar a produtividade em diferentes culturas, inclusive em espécies arbóreas com a E. erythropappus; têm-se desenvolvido diferentes métodos de regeneração, como o de semeadura direta visando o aumento de produtividade. Estes métodos têm requerido altas dosagens de adubações, assim é preciso lembrar que essas adubações tornam o potencial osmótico num componente importante, para a sensibilidade da planta à salinização. Plantas muitos sensíveis à salinidade absorvem água do solo juntamente com sais permitindo que haja toxidez na planta por excesso de sal absorvido, levando as plantas ao estresse hídrico por osmose (Lima, 1997).

Para atender a crescente demanda pelos produtos oferecidos pela E. erythropappus há a necessidade de experimentos fora da sua área de origem e testes para avaliar melhores tipos de adubações evitando assim que a espécie sofra com a salinização provenientes dos índice salinos de cada adubo utilizado no seu desenvolvimento inicial.

Diante disso os objetivos deste estudo foram: i) avaliar a influência do índice salino de diferentes adubos na emergência de plântulas de E. Erythropappus; ii) indicar uma adubação para a semeadura direta desta espécie; iii) avaliar se a emergência de plântulas de candeia acompanham a sua época de dispersão.

\section{MATERIAL E MÉTODOS}

Com intuito de avaliar o desenvolvimento da espécie E. erythropappus fora do local de estudos da espécie decidiu-se instalar o experimento de semeadura direta no município de Inconfidentes situado no sul do estado de Minas Gerais no Instituto Federal de Educação, Ciência e Tecnologia, Campus Inconfidentes. A área selecionada para a implantação do experimento tem como ponto de referência as coordenadas geográficas de $22^{\circ} 19^{\circ} 01,2^{\prime}$ 'S e $46^{\circ} 19^{`} 40,8^{\prime \prime} \mathrm{W}$, apresenta altitude de $869 \mathrm{~m}$, clima Cwa segundo a classificação climática de KOPEN com característica de $\mathrm{Cwb}$, precipitação média de $1744 \mathrm{~mm}$ e temperatura média anual de $20^{\circ} \mathrm{C}$ (Antunes, 1986).

Os experimentos de semeadura direta de sementes de E. erythropappus foi realizado em viveiro na estação de inverno (Experimento 1) e primavera (Experimento 2). A realização dos experimentos em viveiro em épocas distintas teve como objetivo avaliar se a temperatura e a época de dispersão tem efeitos na emergência das plântulas desta espécie.

$\mathrm{O}$ efeito da salinização das diferentes adubações foram avaliadas a partir de 4 tratamentos (esterco bovino; superfosfato simples; NPK 8-28-16; testemunha). Para isso, em um balde foram homogeneizados o volume de solo referente a uma cova com dimensão de $30 \times 30 \mathrm{~cm}$ e o adubo, seguindo as seguintes proporções: 2 litros de esterco.cova ${ }^{-1} ; 50 \mathrm{~g}$ de superfosfato simples.cova ${ }^{-1} ; 50 \mathrm{~g}$ do adubo NPK 8-28-16. cova $^{-1}$ para a obtenção dos substratos. 
Em seguida, os substratos foram colocados em caixas de isopor com dimensões de $15 \times 10 \mathrm{~cm}$ e dispostas seguindo o delineamento Inteiramente Casualizado com quatro repetições.

Em cada caixa de isopor foi realizada a semeadura direta de 100 sementes que foram cobertas por uma camada de substrato peneirado de aproximadamente 2 milímetros.

Os experimentos foram irrigados de acordo com a necessidade do substrato e das plântulas. As irrigações foram feitas no período da tarde por volta das 18 horas, alternando um dia sim e outro não. Quando era observada uma maior temperatura e maior evaporação, aumentava-se o número de irrigação durante o dia.

A avaliação da emergência das plântulas foi realizada diariamente após a semeadura e foram consideradas emergidas as plântulas que apresentaram os protófilos visíveis.

A emergência das plântulas foi avaliada através da porcentagem final da emergência das plântulas e o vigor através do índice de velocidade de emergência (IVE) utilizando a equação de Maguire (1962), a seguir:

$$
I V E=\frac{E_{1}}{N_{1}}+\frac{E_{2}}{N_{2}}+\ldots+\frac{E_{n}}{N_{n}}
$$

onde:

$\mathrm{E} 1, \mathrm{E} 2, \mathrm{En}=$ número de plântulas com protófilos visíveis presentes na primeira contagem, na segunda contagem, até na última contagem.

$\mathrm{N} 1, \mathrm{~N} 2, \mathrm{Nn}=$ número de dias de embebição à primeira, segunda contagem, até a última contagem.

\section{RESULTADOS}

\section{Experimento em viveiro no período de in- verno}

Durante os 30 dias de avaliações no experimento de inverno, não foi verificado emergência de plântulas de E. erytroppapus no substrato contento NPK 8-28-16, mas observou-se emergência de plântulas nos demais substratos avaliados (Figura 1A e Tabela 1). A emergência de plântulas no decorrer dos 30 dias após a semeadura no substrato contendo esterco foi de $4 \%$, de 5,50\% no substrato testemunha e de $12,50 \%$ no substrato contendo adubo superfosfato simples, o qual se sobressaiu estatisticamente pelo teste de Scott-Knott a 5\% de probabilidade (Figura 1A e Tabela 1).

Os maiores valores do IVE calculado para as plântulas no período de inverno ocorreu nos tratamentos testemunha e superfosfato simples, os quais não diferiram estatisticamente entre si, mas diferiram dos tratamentos esterco e NPK 8-28-16 (Tabela 1).

\section{Experimento em viveiro no período de pri- mavera}

Durante os 30 dias de avaliações foi verificada emergência de plântulas de $E$. erytroppapus no substrato contento NPK 8-28-16 de apenas 0,25\%, mas observou-se maior percentual de plântulas emergidas nos demais substratos avaliados. A emergência de plântulas no substrato contendo esterco foi de $31,25 \%$, no substrato testemunha de $37,5 \%$ e no substrato contendo o adubo superfosfato simples de 39,5\% (Figura 1B e Tabela 1). O percentual de plântulas emergidas verificado no substrato contendo superfosfato simples foi superior aos demais percentuais de plântulas emergidas nos demais tratamentos avaliados (Tabela 1).

Em relação ao desvio padrão dos tratamentos testemunha e do tratamento superfosfato simples verificou-se que até o $14^{\circ}$ dia após a semeadura o tratamento testemunha apresentou maior percentual de plântulas emergidas e que desse momento até o $20^{\circ}$ dia após a semeadura não houve diferença significativa entre a emergência destes dois tratamentos. No entanto, a partir do $20^{\circ}$ dia após a semeadura o superfosfato simples superou essa diferença, mostrando que este substrato auxilia de forma positiva na emergência de plântulas das sementes de E. erythropappus. 

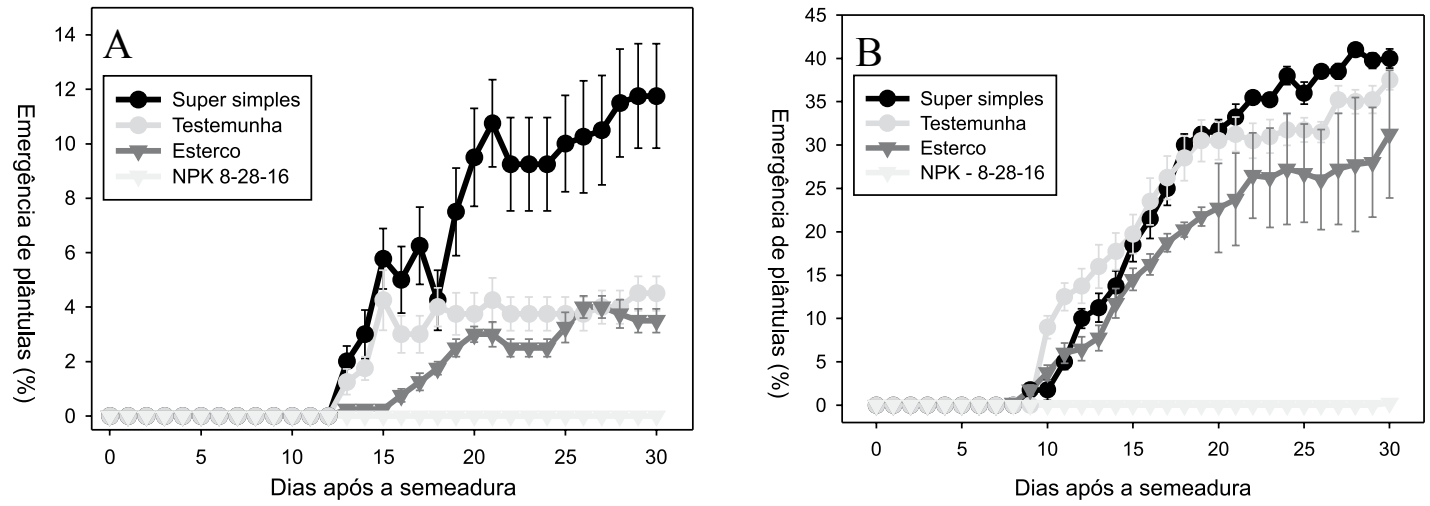

Figura 1. Percentual de plântulas emergidas de E. erythropappus ao longo de 30 dias em diferentes condições de substrato: A) Período de inverno; B) Período de primavera. Pontos representam o percentual médio de plântulas emergidas e as barras os desvios padrões de 4 repetições.

Tabela 1. Porcentagem de plântulas emergidas e índice de velocidade de emergência (IVE) de plântulas de E. erythropappus nos experimentos de semeadura direta em viveiro no período de inverno e primavera. IF Sul de Minas, Campus Inconfidentes, 2007.

\begin{tabular}{ccccccccc}
\hline \multirow{2}{*}{ Tratamentos } & \multicolumn{3}{c}{ Germinação (\%) } & \multicolumn{4}{c}{ IVE } \\
\cline { 2 - 9 } & $\begin{array}{c}\text { Viveiro - } \\
\text { inverno }\end{array}$ & $\begin{array}{c}\text { Viveiro - } \\
\text { primavera }\end{array}$ & $\begin{array}{c}\text { Viveiro - } \\
\text { inverno }\end{array}$ & $\begin{array}{c}\text { Viveiro - } \\
\text { primavera }\end{array}$ \\
\hline $\begin{array}{c}\text { Superfosfato } \\
\text { simples }\end{array}$ & 12,50 & $\mathrm{Ab}$ & 39,50 & $\mathrm{Aa}$ & 4,04 & $\mathrm{Ab}$ & 29,85 & $\mathrm{Aa}$ \\
\hline Testemunha & 5,50 & $\mathrm{Bb}$ & 37,50 & $\mathrm{Ba}$ & 3,06 & $\mathrm{Ab}$ & 28,37 & $\mathrm{Aa}$ \\
\hline Esterco & 4,00 & $\mathrm{Bb}$ & 31,25 & $\mathrm{Ba}$ & 1,22 & $\mathrm{Bb}$ & 20,30 & $\mathrm{Ba}$ \\
\hline NPK 8-28-16 & 0,00 & $\mathrm{Ba}$ & 0,25 & $\mathrm{Ca}$ & 0,00 & $\mathrm{Ba}$ & 0,01 & $\mathrm{Ca}$ \\
\hline
\end{tabular}

Médias seguidas pela mesma letra maiúscula na coluna e minúscula na linha não diferem entre si pelo teste de ScottKnott a 5\% de probabilidade.

O IVE calculado para as plântulas mostrou que não houve diferença significativa entre os tratamentos testemunhas e superfosfato simples, sendo que o tratamento superfosfato simples apresentou um maior IVE que a testemunha. O tratamento Esterco, diferiu dos demais tendo um melhor IVE em relação ao NPK. Já o tratamento NPK foi o de menor IVE, tendo uma diferença significativa entre os demais tratamentos (Tabela 1).

\section{DISCUSSÕES}

O maior percentual de plântulas emergidas nas diferentes estações (inverno e pri- mavera) ocorreu no substrato que continha superfosfato simples, apresentando diferenças significativas em relação aos outros tratamentos avaliados (Tabela 1 e Figuras 1A e 1B).

$\mathrm{O}$ adubo superfosfato simples, que apresenta alto teor de fósforo (18\%), possui baixo índice salino (8) em relação aos adubos nitrogenados, promovendo menor salinização e conseqüentemente menor potencial osmótico, sendo assim a semente não perde tanta água para o meio, tendo maior germinação (Marschner et al., 1986). Essa menor salinização do substrato pode ter promovido a maior emergência de plântulas de E. erythropappus no substrato com adubo superfosfato simples. 
O adubo superfosfato simples pode, portanto, ser considerado o melhor para o início da emergência de plântulas de E. erythropappus.

No substrato com NPK 8-28-16 a não emergência de plântulas no experimento realizado no inverno (Tabela 1 e Figura 1A) e o baixo percentual de emergência de plântulas no experimento realizado na primavera (Tabela 1 e Figura 1B) podem ser explicados pelo fato do substrato possuir $\mathrm{N}$, que segundo Malavolta (1981) é semelhante à uréia onde o índice salino é de 75, e também por conter cloreto de potássio com índice salino de 116. Assim, o alto índice salino proporcionado por estes elementos pode ter promovido aumento na salinidade do meio onde foram semeadas as sementes de E. erythropappus.

Vieira e Ramos (1999) observaram que o aumento da concentração de sais solúveis no solo tem como conseqüência a elevação do seu potencial osmótico, o que pode provocar a transferência de água das sementes para o solo, provocando-lhes murchas e, em casos extremos, a não germinação.

Em estudos realizados com diferentes espécies de leguminosas ( $S$. virgata e $M$. caesalpinifolia) verificou-se que a alta concentração de salinidade provocou grande decréscimo na porcentagem de germinação de M. caesalpinifolia (Sarcinelli et al., 1999). Resultados semelhantes foram encontrados na germinação de pepino (Torres et al., 2000), de arroz (Lima et al., 2005), de mamoneira (Oliveira et al., 2006) e de melancia (Torres, 2007). Afirmando assim a baixa germinação de E. erythropappus quando submetidas a altos teores de salinidade proporcionados pela adubação com NPK 8-28-16.

Segundo Fernandes Júnior e Heloísa (1998) a germinação das sementes é influenciada pelo substrato, pois fatores como aeração, estrutura, capacidade de retenção de água, grau de infestação de patógenos, entre outros, podem variar de acordo com o material utilizado, favorecendo ou prejudicando a ger- minação das sementes. Assim, as diferentes composições dos substratos do presente estudo influenciaram a emergência de plântulas de E. erythropappus.

Oliveira et al. (2006) ao comparar diferentes teores de esterco constatou que o seu índice salino não interfere na germinação da mamoneira. $\mathrm{O}$ índice salino do esterco também não interferiu na emergência de plântulas de $E$. erythropappus visto não ter havido diferença significativa na emergência de plântulas nos tratamentos com esterco e testemunha (Tabela 1, Figuras 1A e 1B). Reforçando este resultado Malavolta (1981) e Marschner et al. (1986) relatam que o índice salino do esterco é considerado insignificante para diversas culturas.

O percentual médio de plântulas emergidas observado no período de inverno foi de $7,33 \%$, resultados estes superados pelo percentual de plântulas emergidas no período de primavera que foi de $36,33 \%$. Estes resultados sugerem que o melhor período de germinação é quando ocorre a dispersão de suas sementes que segundo Scolforo et al. (2005) ocorre nos meses de agosto a outubro. A E. erythropappus não apresenta dificuldades para reprodução, este fato foi relato por Silva (2001) que mencionou que a germinação se dá com 10 dias.

Entretanto Tonetti et al. (2006) e CETEC (1994) observaram em laboratório que a germinação atinge $6 \%$ a $45,75 \%$ a partir de 8 dias após a semeadura. $\mathrm{O}$ resultado da semeadura em viveiro no inverno $(X 5,5)$ e na primavera $(X 27,14)$ foi semelhante aos resultados de Tonetti et al. (2006) e do CETEC (1994).

\section{CONCLUSÕES}

O índice salino do adubo superfosfato simples não interfere na emergência de plântulas de E. erythropappus.

O índice salino do adubo NPK interfere na emergência de plântulas de E. erythropappus. 
O substrato contendo superfosfato simples é indicado para a semeadura direta de E. erythropappus.

A estação da primavera foi a melhor para a semeadura direta de E. erythropappus.

\section{REFERÊNCIAS BIBLIOGRÁFICAS}

ANTUNES, F. Z. Caracterização climática do estado de Minas Gerais. Informe Agropecuário, Belo Horizonte, v.12, n. 138, p. 9-14, Jun. 1986.

ARAÚJO, L.C. Vanillosmopsis erythropappa (DC.) Sch. Bip.: Sua exploração florestal Rio de Janeiro: Escola Nacional de Agronomia, 1944. 54 p.

ATINA - Indústria e Comércio de Produtos Florestais Não Madeireiros S.A, 2009. Comunicação pessoal.

CÂNDIDO, J.F. Cultura da candeia (Vanillosmopsis erythropappa Sch.Bip.). Boletim de Extensão, Viçosa: UFV, 1991. 35 p.

CHAGAS, M. P. FILHO, M. T.; LISI, C. S. Caracterização macro e microscópica da madeira de candeia (Eremanthus erythropappus, Asteraceae). Revista Brasileira de Biociências, Porto Alegre, v. 5, p. 156-158, Jul. 2007. Suplemento 1.

FERNANDES JÚNIOR, F. M.; O. G.; HELOÍSA S. Substratos comerciais e com esterco de curral na produção de mudas de couve-flor. Pelotas, RS: UFPEL/FAEM, 1998.

LIMA, L. A. Efeitos de sais no solo e na planta. In: CONGRESSO BRASILEIRO DE ENGENHARIA AGRÍCOLA, 26., 1997, Campina Grande. Manejo e controle na da salinidade na agricultura irrigada. Campina Grande: UFPB, 1997. p. 113-133.
LIMA, M.G.S. et al. Qualidade fisiológica de sementes de arroz submetidas a estresse salino. Revista Brasileira de Sementes, Pelotas, RS, v. 27, n. 1, p.54- 61, 2005.

MAGUIRE, J.B. Speed of germination-aid in selectino and evaluation for seedling emergence vigor. Crop Science, Madison, v. 2, n. 2. 176-177 p. Mar/Abr. 1962.

MALAVOLTA, E. Manual de química agrícola: substratos e adubação. 30 ed. São Paulo: Agronômica Ceres, 1981. 293 p.

MARSCHNER. H. Mineral nutrition of higher plants. London: academic press inc., 1986. 674 p.

OLIVEIRA, P. M. et al. Efeitos da salinidade da água sobre a germinação de melão. Revista Brasileira de Engenharia Agrícola e Ambiental, v. 2, n. 2, p.235-238. 1998.

OLIVEIRA, M. K. T. et al. Efeito de diferentes teores de esterco bovino e níveis de salinidade no crescimento inicial da mamoneira (Ricinus communis l.). Revista Verde, Mossoró, RN, il) v. 1, n. 1, p. 47-53, Jan./Jun. 2006.

PEDRALLI, G. TEIXEIRA MCB.; NUNES,Y.R. Estudos sinecológicos sobre a candeia (Vnillosmopsis erythropapa Schult. Bip) na estação ecológica do Tripuí,Ouro Preto-MG. Revista Árvore, Viçosa, v. 21, n .2. p. 301-302, 1997.

PÉREZ, J. F. M. Sistema de manejo para candeia (Eremanthus erythropappus) (DC.), Mac Leish. 71 f. Dissertação (Mestrado), Universidade Federal de Lavras, 2001 Lavras, MG.

RIZZINI, C. T. Árvores e madeiras úteis do Brasil: manual de dendrologia brasileira. São Paulo: E. Blüche, 1979. 296 p. 
SARCINELLI, T.S.; RIBEIRO Jr., E. S.; DIAS, L. E. Tolerância à salinidade de sementes de espécies leguminosas utilizadas na recuperação de áreas degradadas. Viçosa, MG: UFV, [19--]. 1999. 4 p.

SCOLFORO J. R.; DONIZETE A. O.; DAVIDE A. C.. Manejo Sustentado das candeias E. erythropappus (DC.) e Eremanthus incanus (Less.). Lavras, MG: UFLA, 2005. 214 p.

SILVA, E. F. Caracterização edáfica e fitossociologia em áreas de ocorrência natural de candeia (Vanillosmopsis erythropappa Scl.Bip. 114 f. Dissertação (Mestrado em Ciência Florestal) Universidade Federal de Viçosa, 2001, Viçosa, MG.

SISTEMA BRASILEIRO DE RESPOSTAS TÉCNICAS - CETEC. Ecofisiologia da candeia: relatório técnico. Belo Horizonte: Sat/ CETEC, 1994. 104 p.

TONETTI, O. A. O; DAVIDE, A. C.; AMARAL da S. E. A. Qualidade física e fisiológica de sementes de E. erythropappus (DC.) MAC. LEISH. Revista Brasileira de Sementes, vol. 28, no 1, p. 114-121 2006.

TORRES, S. B.; VIEIRA, E. L.; MARCOS FILHO, J. Efeitos da salinidade na germinação e no desenvolvimento de plântulas de pepino. Revista Brasileira de Sementes, Brasília, v.22, n.2, p. 39-44, 2000.

TORRES , S. B. Germinação e desenvolvimento de plântulas de melancia em função da salinidade. Revista Brasileira de Sementes, vol. 29, n.3, p. 77-82, 2007.

UNIVERSIDADE FEDERAL DE LAVRAS. Núcleo de Estudos em Manejo Florestal -NEMAF. Sistema de Manejo para candeia ( $E$. erythropappus e Eremanthus incanus). Lavras-MG, 2003.

VIEIRA, R. F.; RAMOS, M. M. Fertirrigação. Comissão de Fertilidade do solo do Estado de Minas Gerais. Recomendações para o uso de corretivos e fertilizantes em Minas Gerais: 50 Aproximação. Viçosa-MG, 1999. p. 111- 130 p. 